\title{
Statistics on the Multinational Corporations as a Means to Exercise Sovereignty
}

\section{Reginald Herbold Green}

Even the longest journey begins with the first step.

Chinese Proverb

The shadow of a man drives the fish but unless there is a net no fish are caught.

\section{West African Proverb}

The development of statistics in relation to the external transactions of peripheral economies, including the internal transactions of MNCs, is a practical question. Its prime aim, at present, is -or should be-the increase of reasonably accurate, rapidly available knowledge, not methodological advances or international comparability for its own sake. Primarily too this knowledge should lead to changing reality, not simply to providing more data for official publication and academic purposes. Because the most central assets and sources of power of $\mathrm{MNCs}$ are control of knowledge and the ability to create additional knowledge, any strategy-other than total withdrawal-for relating to them will be ineffective unless it too gives emphasis to acquiring and applying knowledge.

There are three reasons why conventional published statistics on international transactions may not be very helpful. In the first place, they are usually general rather than specific. Second, the forms of presentation and methods of data collection/analysis may not be appropriate; third, 'international' loses its traditional meaning when many territorially external transactions are internal to MNC groups and many territorially internal transactions are between foreign integrated MNC units and basically domestic ones. We need appropriate sources, usable levels of accuracy and acceptable time lags, ${ }^{1}$ which will depend on the intended use of the data. We also need a framework within which relations with MNCs (including the rejection or ending of relationships) can be made less unequal; this requires data on domestic MNC transactions with other sectors within the national territory and independent baseline data against which inter-

\footnotetext{
1 In many cases there may be a trade-off between accuracy and speed. Accurate analyses of world grain prices 18 months in arrear do not help in planning a six to twelve-month forward food import procurement policy; neither do a handful of quotes from members of a suspected sellers ring. no matter how promptly they can be secured. A sample (even if incomplete and non-random) of major spot and future contracts concluded by major exporters over the past three months is far superior to either for the stated purpose.
}

national transactions (including especially transactions actually within an MNC's transnational company group) can be evaluated.

Many of the data needed are also relevant to other aspects of national planning and policy formulation. Sectoral and large firm transaction and cash flow accounts are critical for national credit budgeting, linkage maximization, and co-ordination of the plans and operations of the parastatal organization in each sector. Because statistical capacity is limited, multi-purpose series and data banks would be useful, as well as coding systems which allow ready retrieval of information when it is needed.2

How the data are presented depends on the user, the use and the size of country. For credit planning in Tanzania data on the $20+$ firms or groups of related firms (18 public sector) using 80 per cent of bank credit are needed separately; for overall public sector analysis, data by main economic activity are appropriate, grouping parastatals in sub-sectors by activity. For India, individual firm data would be quite unmanageable for macro analytical use because of the number of firms, but would be needed for line of activity cross studies or detailed control purposes. In any case the basic data-as opposed to published or circulated presentations-need to be recorded firm by firm and in a format permitting retrieval of data for individual firms when and if needed.

If data for individual firms may not be disclosed under a Statistics Act, which may be copied from an antiquated version of the ex-colonial power's Act, the proper response is to amend the law. To claim that economic management data are unavailable because one's own legal system prevents disclosure totally misinterprets the proper relationship between law and policy. This type of law should flow from policy, and be amended to remain consistent with it, not vice versa. This is not to urge disrespect for the lawsthey should be amended not simply violatedbut to warn against either making fetishes out of statutes or confusing the rule of law with the immutability of laws.

\footnotetext{
2 For example, if import data are coded before compilation a system which allows rapid recovery of all entries for a particular major import for a given period is a minimum need. Otherwise, the only way to secure data on e.g. passenger tyre imports is to sort through every import invoice for the period.
} 


\section{Monitoring of Prices}

Transfer pricing, in the narrow sense of transactions between MNC sub-units, is a major, clearly identified and currently fashionable issue. However, it is not the only obstacle to the exercise of national economic sovereignty or the only problem for statistical offices engaged in building up capacity for exercising it. Transfer pricing is merely one among a number of types of external transaction requiring monitoring (either by random samples or by independent checking of test cases).

Import and export prices may require monitoring even if no interlocking $\mathrm{MNC}$ units are involved. They may reflect differential pricing, collusion, or imperfect (in various senses) markets, and whether or not these give rise to transfer pricing in the formal sense, we need to be able to identify and to analyse the empirical (and ideally the causal) pattern.

The particular structure of production-marketingprocessing may be largely independent of the exact parties engaged in each stage. A national export company that sells a basic export at a price $10-15$ per cent below what brokers would be prepared to pay is an economic incubus no matter the reason. The identification of the pattern of its transactions is a first step toward correction. Similarly a national firm which imports staples by open international tender but receives bids $10-30$ per cent above the going market price needs a statistical reference service. The components of a transaction monitoring system should include:

(a) a transaction codification system, includingat a minimum-product, origin and destination (by country and firm), quantity, quality, dates of contract and delivery;

(b) a system for collecting basic reference prices (and converting them to fob export or cif import equivalents) and acquiring specific prices when needed for checking actual transactions;

(c) guidelines indicating how much deviation of actual from reference prices requires a fullscale spot check;

(d) identification of commodities, companies, countries for which all major transactions (or at least groups of transactions) require checks and a random checking system for less important (or less suspect) transactions;

(e) agreed procedures among statistical units (e.g. Central Statistical Office, Customs Service, Central Bank) and those monitoring transactions (e.g. Central Bank. Treasury. Ministries of Commerce and of Industries, Price Control Commission, public enterprises) to ensure that the right data are collected, the necessary analyses performed, and the appropriate users made aware of the results. It is also necessary to ensure that agreed priorities are maintained, especially in cases of scarce time/personnel.

A few examples may illustrate what is needed. First, it is possible for most major primary products to run checks between world market prices and average fob value of exports (or subsequent remittances if the exact value cannot be known at export because of the marketing structure). One would need to take account of quality, shipping, insurance, reasonable marketing costs/surpluses, delays between shipment and sale etc., but for routine checking adequate comparability can be secured fairly readily. For example, in the case of Tanzania, cotton auction prices (ex-Mwanza) have averaged about 10-15 per cent below Liverpool, well within reasonable trader costs and margins. For coffee the margin has been 20-25 per cent with some problems in adjusting for quality and secret rebates from the nominal sale price granted by at least one major exporting country. In this case the Coffee Board has introduced a direct European selling outlet integrated into the auction system, leading to some improvement in prices. In the case of sisal the discrepancy has been wider and at one point was 30-70 per cent according to the exporting firms. Spot checks were made and action taken under Exchange Control powers to prohibit exports for which an unreasonable remittance would be made. Tea auction prices in Nairobi are apparently 30-35 per cent below London-a clear indication that some action is needed. (As it happens none of these examples involve transfer prices in the technical sense of the term.) Second, in the case of basic raw materials and intermediate goods, two types of check are possible. One is to compare transactions of MNC-linked and independent firms within the country. If a textile mill buying from a related supplier pays one and a half times as much for dye as an independent mill and uses twice as much per unit of output, there is a prima facie case for detailed checking. ${ }^{3}$ Alternatively world prices for these products can be handled like commodity data to produce reference check series. Studies by the Andean Pact secretariat ${ }^{4}$ 3 This case illustrates the potential for multiple use of
ttatistical data on business transactions. The first mill is
prima facie wasting dye, and queries as to its managerial
competence are in order especially if, as in this actual case,
the public sector holds the majority of the shares.
4 Discussed in detail in C. Vaitsos, Intercountry Income
Distribution and Transnational Enterprises, Clarendon,
Oxford, 1974, Ch. IV, V. VI and Power, Knowledge and
Development. Policy' in G. K. Helleiner, (ed.) A World
Divided: The less Developed Countries in the International
Economy, Cambridge, forthcoming. 
show that very great overpricing of standard materials, e.g. rubber, and intermediate inputs, e.g. pharmaceutical chemicals, is common. It is not irrelevant to note that, while overpayment by domestically-owned units is less, it is still significant, indicating the need for better market intelligence.

In the case of major transactions and transaction groups an historic series is useful for checking shifts in relationships. For example, the ratio of raw cashew nut cif export prices from Tanzania to kernel prices in the New York market was one to seven or eight for several years. It then declined to one to fourteen, following the creation of a purchasing monopoly by the main buyer. The series alerted the Central Bank, the Treasury and the exporter to the need for tougher negotiations, and yielded preliminary clues on what would be a fairer price. After further analysis higher prices were in fact obtained. ${ }^{5}$

At first sight it often seems that data are not available or not comparable. But it is rarely impossible to compute a reference series adequate for detecting unusual transfer prices:

(a) commodities (including many semi-processed inputs) do have fairly genuine market prices which can be procured from commodity press services (e.g. Reuters) and the financial newspapers;

(b) true costs (inclusive of profit margins) can be built up from public data for some MNC imports-e.g. crude oil costs starting with royalty and tax payments, production cost, refining cost, and freight; then a reasoned dialogue can be held on allowable import and domestic selling prices (i.e. on total margins), and on what share of the profits will be retained in the country operating the check system;

(c) many trade journals publish data, or the basis for calculating them, and these can be accumulated by a specialist statistical unit;

(d) various official publications (e.g. of anti-trust bodies and the Securities and Exchange Commission in USA) provide data on domestic and export prices in surprising detail;

(e) banks (through their correspondents) and nationally owned trading companies can secure spot data;

5 The check here is indirect. The raw nut market is de facto an oligopoly-oligopsony with Tanzania, Mozambique and Kenya as sellers and India, peripherally Brazil and local processors as buyers. However, there is no technical reason why raw nut/kernel ratios should vary greatly, since neither the conversion ratio nor processing cost as a share of kernel proceeds has changed significantly. (f) equivalent products can be used for most standard consumer goods e.g. similar brands of tinned fish sold to several markets;

(g) in important cases reconstructions can be carried out e.g. a $£ 1,000$ automobile cif Africa in 1970 incorporated about $£ 600$ of parts (subtracting other costs); the price of spares cumulated for a complete car came to about $£ 2,400$; the discount allowed for parts omitted when incomplete kits were imported to allow local assembly (using some local components) implied $\mathfrak{£ 2 4 0}$ of parts. For initial bargaining on reductions from kit costs to allow for use of local elements in assembly, $£ 600$ would be a useful starting point. For spare pricing it would also be relevant, although if the companies took their profits on spares-rather than new cars-this figure would not be definitive. However approximate such reconstructions, they provide far better identification of the area for bargaining and of possible target gains than can be obtained without them.

The same principles apply to other types of transaction. If an MNC subsidiary were historically in debt on current account to its head office, but the series showed that, following partial nationalization and tight exchange/dividend control, it had moved into large and increasing credit, an alarm bell should ring. It is not much use chasing minor exchange control violaters and allowing this type of respectable mass evasion to pass unnoticed.

When major evasions are discovered, various actions are possible: calling local overdraft to force repatriation of funds; tightening export remittance control; prosecution for fraud. If a loophole exists in the legal regulations, then amendments can and should be made. The data series can help both to pinpoint what needs to be made unlawful and to give laws the preventative power that comes only with a significant danger of being found out.

The borderlines between statistical collection, detailed case studies and the processes of economic management, legislation, using a special unit for control of corporations, creating new business businesses, dialogue and negotiation are not precise. Nor will they be the same from country to country or for each class of case.

All three stages might be conducted for some transactions in some countries by the Central Bank. In other circumstances, commodity prices might be checked by a Statistical Office; detailed 
case studies made by domestic (or speciallyselected foreign) consultants; policy decided by a joint team comprising the Central Bank, the Treasury, the ministries of Agriculture and the domestic exporter (or Commodity Board). What matters is an agreed set of channels for forwarding data (with direct personal communication on critical and urgent discoveries) plus a known set of decision-making responsibilities for different stages and types of transaction.

The resources required to build up the system sketched above will not be inconsiderable. ${ }^{6}$ However, it would be most surprising if their regular use on main transactions could not-over a period of several years-result in 5-10 per cent average savings on import prices and corresponding gains on exports, with far larger savings in some cases. Further, the greater understanding of the nature of the transaction patterns and markets will provide a base for more informed economic management by government and/or public sector enterprises.

Several questions arise on the practicability of the approach outlined and its value to peripheral economies. All of the areas discussed are ones in which partial successes have been secured by the Andean Pact countries, Mexico, Tanzania or Jamaica, and these show that the statistical base needed can be secured without heavy costs and can be used to extract significant gains. Certainly there are differences between the capabilities of different peripheral countries. However, statistical capacity for specific purposes can be developed anywhere fairly rapidly. It is largely a matter of statistical priorities which statistics are developed or maintained-some existing statistical series may well be of no very evident use but tie up scarce personnel and data processing capacity.

Improved statistics will not by themselves create a New International Economic Order. Unless there is the will, the political base and the negotiating capacity to use them for altering unequal relationships, these relationships will not be altered. However, in the absence of better knowledge, political will and negotiating capacity can achieve little. In respect of some aspects of international economic relations-e.g. transfer pricing-statistical knowledge is a necessary (even if clearly not a sufficient) condition for negotiating or imposing change efficiently. In the

6 Subcontracting to specialist firms--as several African governments have done-is not very satisfactory. In practice the price ranges they approve are quite wide, their fees large and their checking weak. In one African country crude petroleum imports overpriced by about 25 per cent were approved and 20 consecutive knocked down vehicle kit approved and 20 consecutive knocked down vehicle kit
shipments carried certificates of checking-it turned out that in none of them were the contents as described. absence of such knowledge, either what is possible will not be achieved or what is not possible will be attempted-costly in either case.

Some changes in the international economic system do not turn primarily on better data-e.g. substitution of SDRs for reserve currencies or increased domestic processing of material exports. Even in these cases better data may be usefule.g. in demonstrating the logic of exporting cocoa as butter, powder or liquor in preference to, or in addition to, raw beans. To argue that more statistical knowledge is critical in some areas but not in others is to prepare a first draft of statistical priorities, not to write off statistics as irrelevant.

\section{The Role of International Organizations}

International organizations can play a role in providing some of the data needed for understanding, regulating and publicizing international and MNC transactions. Clearly global series are needed. UNCTAD is taking some tentative initiatives toward reference price collection and prompt publication: these should be followed up. The World Bank's capacity for detailed productby-product analysis of price trends should be used more systematically and made generally accessible. The role of international organizations is limited, however. This is not because of minor institutional bottlenecks but their basic nature. They must pay some regard to the perceived interest of all significant members. If they are fully committed to any group they cannot retain effectiveness in their unique role as honest brokers, mediators, achievers of partial syntheses.

Second, they are designed to collect and process data on a broad front for broad uses, not to secure individual items for specific uses. In particular they are usually not able to achieve the speed and evaluation of specific transactions and data sources necessary for providing specific knowledge oriented to business transactions, because they are more bureaucratic and less operational than functional governmental unitsthough perhaps not than the most isolated and autonomous national statistical offices. Business management --even at the macro economic level - is not one of the UN areas of expertise.

The work of international agencies can certainly complement that of national governments, but there will still be a need for national capacity to provide the analysis and interpretation necessary for applying knowledge from a committed bargaining position; to secure particular data for particular uses; and to integrate national statistical development into the development of national economic management and planning. 


\section{Selected Background Material}

Adam, G. 'Some Implication and Concomitants of World-wide Sourcing', Acta Oeconomica 8, 1971.

Barnet, R. J. and Muller, R. E. Global Reach, Simon and Schuster, New York, 1974.

Helleiner, G. K. 'Manufactured Exports from Less Developed Countries and Multinational Firms', Economic Journal, March 1973.

Meier, G. M. Problems of Co-operation For Development, OUP, 1975.
Moran, T. H. 'Transnational Strategies of Protection and Defence by Multinational Corporations', International Organizations No. 27, 1973.

Streeten, P. 'The Multinational Enterprise and the Theory of Development Policy', World Development, Vol:" 1, No. 10, 1973.

United Nations, Multinational Corporations in World Development, New York, 1973.

Vaitsos, C. Intercountry Income Distribution and Transnational Enterprises, Clarendon, Oxford, 1974. 